\title{
Development of congestive heart failure after treatment with metoprolol in acute myocardial infarction
}

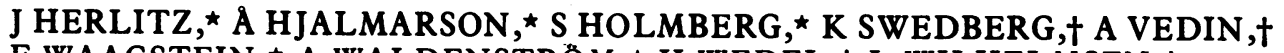

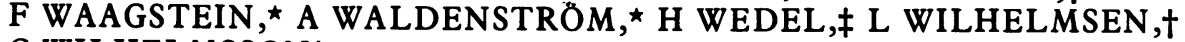 \\ C WILHELMSSON†
}

From the ${ }^{\star}$ Department of Medicine I, Sahlgren's Hospital, the †Department of Medicine, Östra Hospital, and the $\ddagger$ Nordic School of Public Health, Göteborg, Sweden

SUMMARY In a double blind study of metoprolol in the treatment of suspected acute myocardial infarction 698 patients (study group) received metoprolol and 697 a placebo (control group). Metoprolol was given in an intravenous dose of $15 \mathrm{mg}$ as soon as possible after admission to hospital followed by $50 \mathrm{~g}$ by mouth four times a day for two days and thereafter $100 \mathrm{mg}$ twice a day for three months. A placebo was similarly given. Congestive heart failure occurred in a similar percentage of patients in both the study (27\%) and the control groups (30\%). Its severity was estimated by calculating the total dose of frusemide given during the first four days in hospital. Less frusemide was given to patients treated with metoprolol compared with those given a placebo in the total series. An appreciably lower total dose of frusemide was given to patients included in the trial $\leqslant 12$ hours after the onset of pain and treated with metoprolol compared with a placebo, while no difference was seen among patients treated later. The initial heart rate, systolic blood pressure, and infarct site affected the results.

One of the main complications in acute myocardial infarction is congestive heart failure. Certain factors suggest that the size of the infarction greatly influences the incidence and severity of congestive heart failure..$^{-3}$ Limitation of infarct size aims at reducing mortality and the incidence of different complications associated with infarct size. Several studies have indirectly shown that infarct size may be limited by different types of intervention, ${ }^{4-6}$ including beta blockade. ${ }^{7-9}$ In most studies few data on the incidence of complications have been reported. In a few trials, however, results have indicated that fewer complications associated with indirect signs of infarct limitation occur. 68

We report the effects of a double blind trial with metoprolol or placebo on the incidence and the severity of heart failure after myocardial infarction in the total series of patients and in various subgroups formed retrospectively. The results in relation to mor-

Requests for reprints to Dr J Herlitz, Department of Medicine I, Sahlgren's Hospital, S-413 45 Göteborg, Sweden.

Accepted for publication 11 October 1983 tality and indirect signs of infarct size in this trial have been reported. ${ }^{10} 11$

\section{Patients and methods}

A total of 1395 patients aged $40-74$ years with suspected acute myocardial infarction were included in the trial. The patients were admitted to the coronary care unit at Sahlgren's Hospital and Östra Hospital, Göteborg, and Skövde Hospital. The inclusion criteria were chest pain of acute onset and of at least 30 minutes' duration or electrocardiographic signs of acute myocardial infarction with estimated onset of infarction within the previous 48 hours.

Treatment was started as soon as possible after arrival in hospital. In $69 \%$ of the patients treatment was started $\leqslant 12$ hours after the onset of pain. Metoprolol was given in a dose of $15 \mathrm{mg}$ intravenously $(5 \mathrm{mg}$ at a time with two minute intervals between injections) followed by $50 \mathrm{mg}$ orally every six hours (first dose 15 minutes after the last injection) for $\mathbf{4 8}$ hours and then $100 \mathrm{mg}$ twice daily for three months. A placebo was similarly given.

The cardiovascular contraindications to inclusion in 
the trial were: a systolic blood pressure $<100 \mathrm{~mm} \mathrm{Hg}$, a heart rate $<45$ beats/min, atrioventricular block $(\mathrm{PQ}$ interval $\geqslant 0.24 \mathrm{~s}$ ), or severe congestive heart failure auscultatory pulmonary rales $>10 \mathrm{~cm}$ above the lung bases). Some further contraindications have been reported elsewhere. ${ }^{10}$ The treatment doses were usually halved and, if no improvement occurred treatment was stopped, if $(a)$ the systolic blood pressure fell below $90 \mathrm{~mm} \mathrm{Hg},(b)$ the heart rate fell to less than 40 beats/min, or (c) if atrioventricular block (PQ interval $\geqslant 0.26 \mathrm{~s})$ or $(d)$ severe heart failure occurred despite optimal treatment. The number of patients withdrawn from treatment for different reasons has been reported elsewhere. ${ }^{10}$ Baseline characteristics of the two groups have already been reported ${ }^{10}$ and were similar.

\section{MYOCARDIAL INFARCTION}

A definite myocardial infarction was diagnosed in 809 patients and a possible myocardial infarction in 162 during the first three days of admission. Of the patients with a definite myocardial infarction, 346 had an anterior and 302 an inferior infarction.

Definite infarction-Two of the three following criteria had to be fulfilled for a diagnosis of definite myocardial infarction: (a) chest pain of at least 15 minutes' duration; (b) development of a $Q$ wave or appearance or regression of ST segment elevation followed by a $T$ wave inversion in at least two leads in a 12 lead standard electrocardiogram or electrocardiographic changes in only one lead and at least one measurement of heat stable lactate dehydrogenase (E.C. 1.1.1.27) activity above a discriminatory level (4.3 $\mu \mathrm{kat} / \mathrm{l})(658.0 \mathrm{IU} / \mathrm{l}) ;(c)$ at least two measurements of serum aspartate aminotransferase (E.C.2.6.1.1.) activity above a reference level $(0.7 \mu \mathrm{kat} / \mathrm{l})(42.0 \mathrm{IU} / \mathrm{l})$ with a lower or normal measurement of serum alanine aminotransferase (E.C.2.6.1.2.) activity or one raised measurement of aspartate aminotransferase activity and at least one raised measurement of heat stable lactate dehydrogenase activity.

Possible infarction-This was diagnosed if there was chest pain of at least 15 minutes' duration together with any of the following: (a) T wave inversions; $(b)$ at least one raised measurement of heat stable lactate dehydrogenase activity; $(c)$ one raised measurement of serum aspartate aminotransferase activity; (d) $\mathrm{Q}$ wave or appearance or regression of ST segment elevation followed by a $T$ wave inversion in one lead in a 12 lead standard electrocardiogram.

Anterior, inferior, and other infarction-Anterior infarction was diagnosed if the criteria for definite infarction were fulfilled and a $Q$ wave or $S T / T$ wave changes in leads V1-V5 (12 lead electrocardiogram) were observed. Inferior infarction was diagnosed if similar changes were observed in leads II, III, or aVF.
Patients were classified as having "other" myocardial infarction if the criteria for definite infarction were fulfilled and there were electrocardiographic changes in both the anterior and inferior wall, electrocardiographic changes only in the lateral wall (I, VL, V6, V7), or no electrocardiographic changes indicating acute myocardial infarction.

Enzyme estimations-The heat labile isoenzymes of lactate dehydrogenase were inactivated according to Brydon and Smith. ${ }^{12}$ Enzyme measurements were determined according to the Scandinavian Committee on Enzymes. ${ }^{13}$

\section{CONGESTIVE HEART FAILURE}

The presence of congestive heart failure (yes or no) during admission to hospital (including the short period in hospital before the start of treatment) was assumed, if any of the following were present: $(a)$ auscultatory rales (more than sparse basal rales); (b) pathological radiographic findings (enlarged left ventricle, dilated pulmonary vessels) (an $x$ ray examination was performed routinely in patients with definite myocardial infarction about one week after admission to hospital; in only a few patients was a radiographic examination performed during the first few days-in these cases portable anteroposterior $x$ ray films were used); and (c) pulmonary oedema on chest radiography. Data on the incidence of congestive heart failure were given in the data record form in 1361 (98\%) patients. Tolerance, including heart failure, was chosen as a secondary endpoint in the initial design of the study. The actual definition of heart failure was decided before the start of the trial.

To estimate the severity of congestive heart failure the total dose of frusemide given during the first four days in hospital (including the short period in hospital before the start of treatment) was calculated. The reason for analysing frusemide treatment only during the first four days was that after the first few days in hospital it is sometimes given routinely regardless of the severity of congestive heart failure in the initial phase. Data were not collected from patients taking frusemide during admission to hospital who were already receiving long term treatment before inclusion, since many of them were given their standard dose of frusemide regardless of the presence of congestive heart failure. Data were not collected from patients receiving additional diuretics other than spironolactone. Other treatment for congestive heart failure included digitalis and, in extremely few patients, vasodilators. Frusemide was, however, first line treatment for congestive heart failure in all the three hospitals participating in the trial. Data on the total dose of frusemide given during the first four days were available for $1105(79 \%)$ patients. 


\section{STATISTICAL METHODS}

Fisher's permutation test and Fisher's exact test in a fourfold table were used. A two tailed test was used. The set of possible hypotheses in this study were not all preconstructed in the protocol. Because of the large number of $p$ values calculated here, the problem of multiple significance tests must be taken into account. A formal significance level is therefore not given. A crude but pessimistic rule is that the number of hypotheses tested times the significance level gives the possible number of falsely declared significances. A reasonable, but informal, method is also to take into consideration other supporting or contradictory results for the final judgment. Results are expressed as mean \pm standard error of the mean (SEM).

\section{Results}

Of 1395 patients included in the trial, 698 received metoprolol (study group) and 697 a placebo (control group).

\section{CONGESTIVE HEART FAILURE}

A similar incidence of congestive heart failure was observed for the two groups (study group, 27.4\%; control group, 29.7\%; Fig. 1). Clinical signs of congestive heart failure before inclusion in the trial (pulmonary rales) were observed in $11.6 \%$ in the study
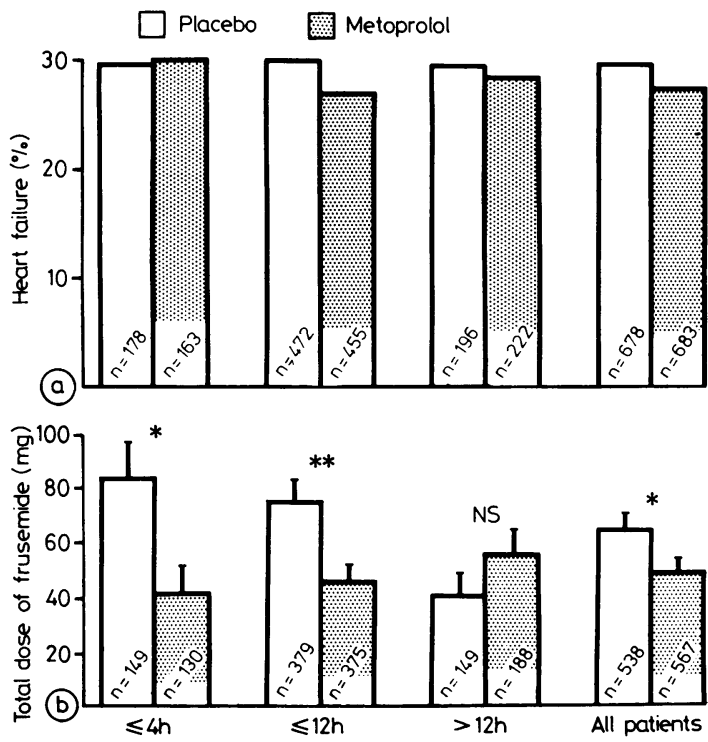

Fig. 1 (a) Incidence of congestive heart failure during admission to hospital and (b) total dose of frusemide given during the first four days in all patients and in subgroups according to the time from the onset of pain to the start of treament in patients given either metoprolol or a placebo (data were missing in 15 patients in $(a)) . \star p<0.05 ; \star \star p<0.01$.
Table 1 Incidence of congestive heart failure according to various definitions in 698 patients given metoprolol (study group) and 697 given a placebo (control group). Figures are percentages

\begin{tabular}{llll}
\hline & $\begin{array}{l}\text { Control } \\
\text { group }\end{array}$ & $\begin{array}{l}\text { Study } \\
\text { group }\end{array}$ & Probability \\
\hline $\begin{array}{l}\text { Auscultatory rales } \\
\text { Radiographic signs }\end{array}$ & 21.5 & 17.1 & 0.047 \\
$\begin{array}{l}\text { (pulmonary vessel dilatation) } \\
\text { Auscultatory rales and } \\
\begin{array}{l}\text { radiographic signs } \\
\text { Pulmonary oedema }\end{array}\end{array}$ & 1.9 & 3.1 & $>0.2$ \\
\hline
\end{tabular}

group compared with $9 \%$ in the control group $(p>0.2)$. The occurrence of congestive heart failure in patients in whom there was no sign of congestive heart failure before inclusion was $21 \%$ in the study group compared with $25.5 \%$ in the control group ( $p>0.2)$. When the incidence of congestive heart failure is analysed according to the various definitions used (Table 1) fewer patients in the study group developed auscultatory rales $(p=0.047)$ despite the fact that they were more commonly heard before the start of treatment compared with the control group. Slightly more study patients had radiographic signs of congestive heart failure $(p>0.2)$. Pulmonary oedema was observed in $0.7 \%$ in the study group compared with $1 \%$ in the placebo group $(p>0 \cdot 2)$. The incidence of congestive heart failure in patients receiving chronic diuretic treatment before admission was $\mathbf{2 8 . 8 \%}$ in the study group compared with $33.3 \%$ in the controls ( $p>0.2$ ).

The mean total dose of frusemide given during the first four days was $49 \pm 5 \mathrm{mg}$ in the study group compared with $65 \pm 6 \mathrm{mg}$ in the placebo group $(p=0.040$; Fig. 1). Frusemide was given in hospital before the trial to $\mathbf{1 0 . 8 \%}$ of the study group compared with $\mathbf{9 . 8 \%}$ in the control group. When the patients with no sign of congestive heart failure before randomisation are separately analysed the mean dose of frusemide given to the study patients was $29 \pm 4 \mathrm{mg}$ compared with $51 \pm 5 \mathrm{mg}$ to the controls $(\mathrm{p}<0.001)$.

During the first four days digitalis was given to $17.5 \%$ of the study patients compared with $23.2 \%$ of the controls $(p<0.01)$. During admission to hospital, three patients in each group were withdrawn from the trial because of congestive heart failure, while four in the study group compared with seven in the control group were withdrawn because of congestive heart failure during the trial period.

Delay in treatment

A similar incidence of congestive heart failure was observed in the two groups regardless of the delay in treatment with either metoprolol or placebo (Fig. 1). A lower mean dose of frusemide given in the study patients treated $\leqslant 12$ hours after the onset of pain $(46 \pm 6 \mathrm{mg})$ compared with that in the controls $(75 \pm 8$ 
$\mathrm{mg} ; \mathrm{n}=754 ; \mathrm{p}=0.003$ ), whereas no difference was observed in patients treated after 12 hours (Fig. 1b). In patients treated $\leqslant 4$ hours after the onset of pain the mean total dose of frusemide was $42 \pm 10 \mathrm{mg}$ in the study group compared with $84 \pm 13 \mathrm{mg}$ in the controls $(n=279 ; p=0.011 ;$ Fig. 1b).

\section{Initial heart rate}

As can be seen in Fig. 2, the difference in the incidence of congestive heart failure as well as in the total dose of frusemide was mainly due to the effect in patients with a high initial heart rate. In those with heart rate $>80$ beats/min the mean dose of frusemide was $82 \pm 14 \mathrm{mg}$ in the study group compared with $135 \pm 17 \mathrm{mg}$ in the placebo group $(n=167 ; p=0.018)$, but there was no tendency to a negative effect in any group.

\section{Initial systolic blood pressure}

Fig. 2 also shows that the most substantial difference in the incidence of congestive heart failure and the total dose of frusemide was observed in patients with a higher initial systolic blood pressure. In those with an initial systolic blood pressure $>160 \mathrm{~mm} \mathrm{Hg}$ the incidence of congestive heart failure was $23.7 \%$ in the study group compared with $35.6 \%$ in the control

Table 2 Total dose of frusemide given during the first four days in hospital in patients treated with metoprolol (study group) and those given a placebo (control group) according to different variables. Figures are means $\pm S E M$ (numbers of patients in parentheses)

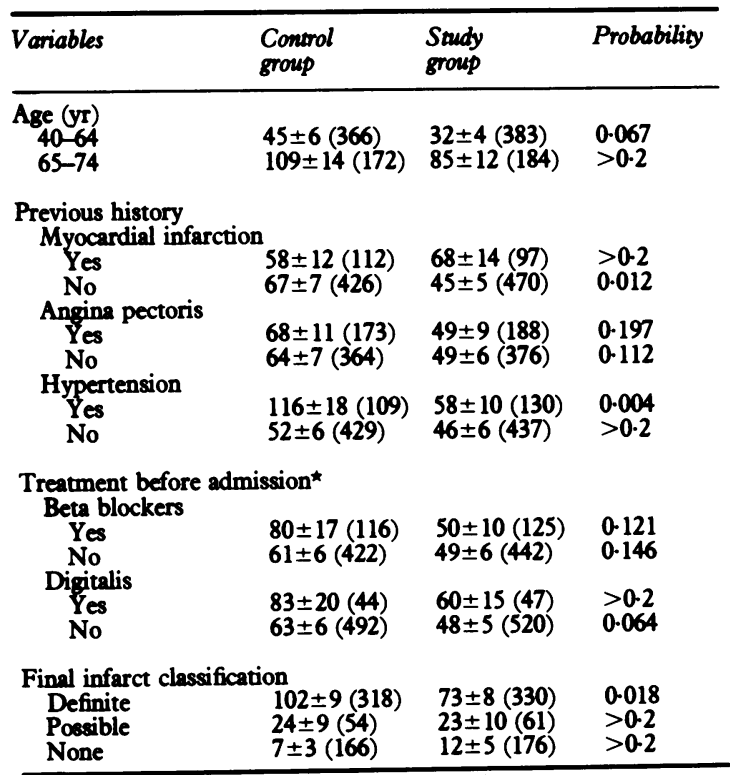

^Date missing on angina pectoris and digitalis in four and two patients respectively. group $(p=0.046)$. The mean dose of frusemide in these patients was $32 \pm 9 \mathrm{mg}$ for the study group compared with $79 \pm 16 \mathrm{mg}$ for the control group $(n=213$;
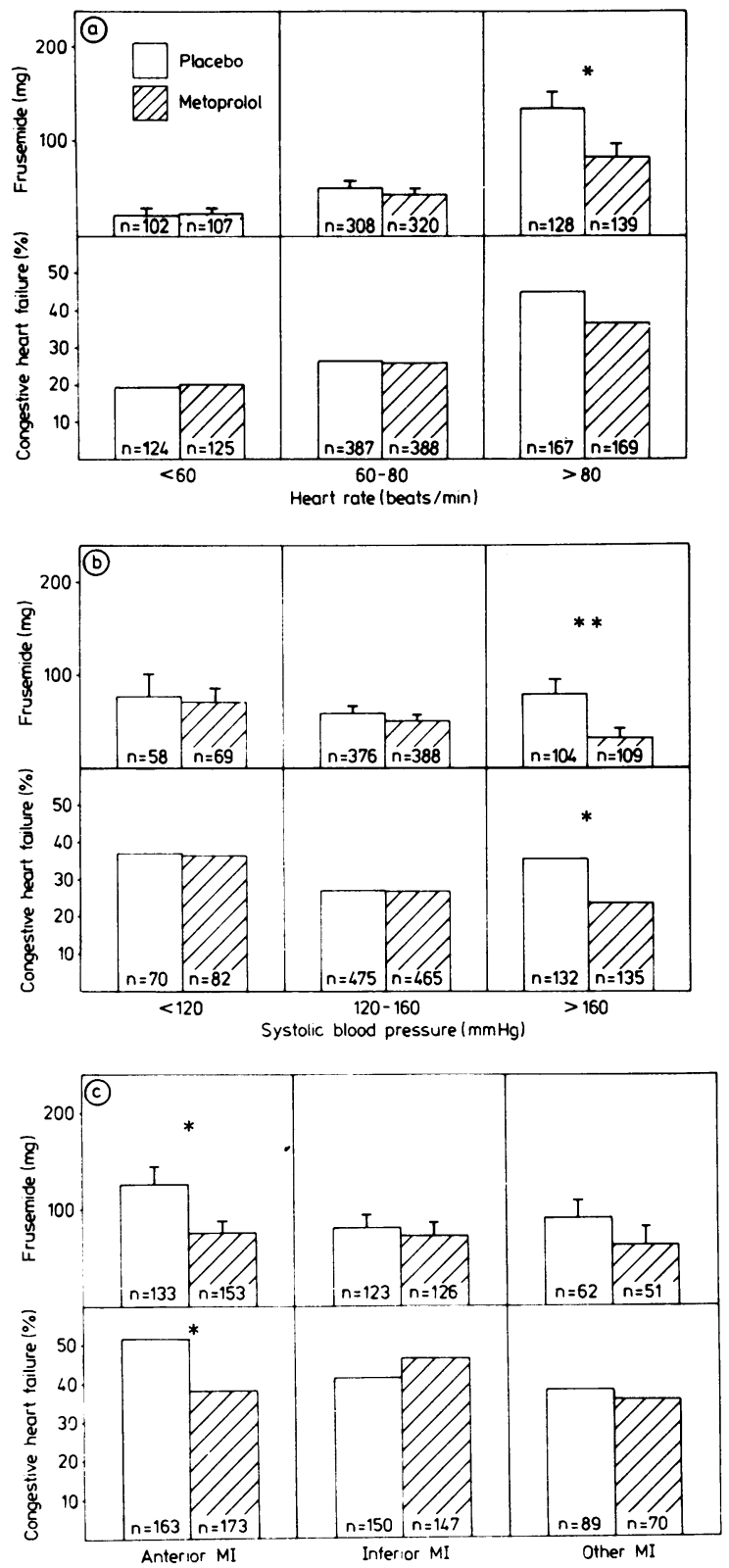

Fig. 2 Incidence of congestive heart failure during admission to hospital and the mean total dose of frusemide given during the first four days in hospital in relation to $(a)$ heart rate and (b) systolic blood pressure immediately before the start of treatment and $(c)$ infarct $(M I)$ site (determined electrocardiographically) in patients treated with either metoprolol or placebo. ${ }^{\star} p<0.05$; $\star \star p<0.01$. 
Table 3 Total dose of frusemide given during the first four days in hospital in patients treated with metoprolol (study group) and those given a placebo (control group) according to different characteristics before the start of treatment. Figures are means $\pm S E M$ (numbers of patients in parentheses)

\begin{tabular}{|c|c|c|c|}
\hline Characteristics & $\begin{array}{l}\text { Control } \\
\text { group }\end{array}$ & $\begin{array}{l}\text { Study } \\
\text { group }\end{array}$ & Probability \\
\hline \multicolumn{4}{|l|}{ Electrocardiographic } \\
\hline $\begin{array}{l}\text { None } \\
\text { ST/T wave } \\
\text { Q wave }\end{array}$ & $\begin{array}{l}27 \pm 4(265) \\
65 \pm 12(152) \\
149 \pm 18(120)\end{array}$ & $\begin{array}{l}24 \pm 5(271) \\
58 \pm 12(152) \\
86 \pm 11(144)\end{array}$ & $\begin{array}{l}>0.2 \\
>0.2 \\
0.002\end{array}$ \\
\hline \multicolumn{4}{|l|}{ Signs of infarction } \\
\hline $\begin{array}{l}\text { Anterior } \\
\text { Inferior }\end{array}$ & $\begin{array}{l}118 \pm 16(142) \\
94 \pm 15(106)\end{array}$ & $\begin{array}{l}71 \pm 10(158) \\
86 \pm 15(109)\end{array}$ & $\begin{array}{l}0.014 \\
>0.2\end{array}$ \\
\hline \multicolumn{4}{|c|}{ Signs of heart failure } \\
\hline $\begin{array}{l}\text { Auscultatory rales } \\
\text { No auscultatory rales }\end{array}$ & $\begin{array}{l}215 \pm 35(46) \\
s 51 \pm 5(485)\end{array}$ & $\begin{array}{l}193 \pm 24(60) \\
29 \pm 4(498)\end{array}$ & $\begin{array}{l}>0.2 \\
<0.001\end{array}$ \\
\hline
\end{tabular}

*Data missing on ECG changes and signs of heart failure in one and 16 patients respectively.

$p=0.008)$. There was no tendency to a negative effect of metoprolol in any of the subgroups.

\section{Infarct site}

When the site of the infarction according to electrocardiographic changes during the first three days in hospital is considered, the most notable effect occurred in patients with an anterior myocardial infarction (Fig. 2). In this subgroup congestive heart failure was found in $38.2 \%$ of the study patients compared with $51.5 \%$ of the controls $(n=336 ; p=0.018)$. The mean dose of frusemide was $76 \pm 11 \mathrm{mg}$ in the study group compared with $127 \pm 17 \mathrm{mg}$ in the controls $(\mathrm{n}=286$; $\mathrm{p}=0.011)$. Similar results were found in patients with "other" myocardial infarction, while no clear cut difference was observed in patients with an inferior myocardial infarction; the incidence of congestive heart failure was slightly higher in the study group ( $>0.2$ ), but the total dose of frusemide was slightly lower $(p>0 \cdot 2)$.

\section{Effect of metoprolol}

According to different baseline characteristics as well as the final diagnosis, some further subgroups were analysed. The main purpose was to evaluate whether in certain subgroups the severity of congestive heart failure seemed to increase after treatment with metoprolol. As can be seen in Tables 2 and 3, in none of the subgroups was a higher total dose of frusemide required after metoprolol treatment. In all subgroups but two a lower total dose of frusemide was given to the study patients compared with the controls.
Discussion

The conventional treatment of patients with myocardial infarction is directed principally at correcting complications such a heart failure, arrhythmias, and atrioventricular block. A different approach is to attempt to influence the natural evolution of the impending myocardial necrosis possibly by interrupting this process in its reversible phase, thereby limiting the final size of the infarction. The aim of such intervention is to reduce mortality and the incidence of complications.

The diagnosis of congestive heart failure based on clinical judgments, such as auscultation and radiographic findings, might be incorrect in a few patients. An attempt further to grade the severity of congestive heart failure by analysing the total dose of frusemide given during the first four days in hospital has limitations. This is an indirect way of estimating the severity of congestive heart failure which must be interpreted with caution since it is open to bias. In these hospitals frusemide is the diuretic drug used for congestive heart failure in acute myocardial infarction with few exceptions, and the administration of diuretics is the first line treatment when congestive heart failure develops. In this study vasodilators were used only exceptionally, and frusemide was rarely given to lower the blood pressure. The difference between the two groups in relation to systolic blood pressure was also quite small.

Less frusemide was given during the first four days to patients treated with metoprolol $\leqslant 12$ hours after the onset of pain compared with those given a placebo. This agrees with previously reported results showing lower enzyme activities in patients given metoprolol who are treated early. ${ }^{11}$ When the incidence of congestive heart failure in the same group of patients was analysed, no difference was found. When the presence of congestive heart failure was analysed we did not take into account, however, whether the patient had pulmonary oedema or less severe failure.

In addition to the delay in treatment with metoprolol initial heart rate as well as systolic blood pressure were important in the results. The difference between the two groups regarding the incidence and severity of congestive heart failure was confined to patients with a higher initial heart rate and a higher initial systolic blood pressure. Infarct site might also be important. Fewer problems with heart failure were observed in patients treated with metoprolol with an anterior infarction-similar results being found in those with "other" myocardial infarction-while no difference was observed in those with inferior infarction. These results support the theory that patients with a higher initial sympathetic tone or no raised parasympathetic tone benefit most from treatment with beta blockade 
in acute myocardial infarction.

In many countries the presence of auscultatory rales is not regarded as strong evidence of congestive heart failure. In the present study, however, the presence of rales before inclusion in the study, interpreted as congestive heart failure, was strongly associated with mortality at three months (unpublished data). In the total series there was a lower incidence of auscultatory rales in the metoprolol group which was also reflected in a lower total dose of frusemide. Overall there was a lower incidence of radiographic signs of congestive heart failure compared with the occurrence of rales, and no difference was found between the two groups. It must, however, be emphasised that in most instances the radiographic examination was performed a couple of days after admission to hospital and at that time heart failure was often already successfully treated.

The use of frusemide may possibly have been biased by heart rate (doctors having a tendency to give more diuretics to patients with a high heart rate). If so, it is difficult to explain why we found a difference only in patients treated early with metoprolol.

Our results agree with those found when the effect of metoprolol on the estimated infarct size is analysed. ${ }^{11}$ A positive correlation was also observed between the estimated infarct size and the incidence and severity of congestive heart failure in patients with a first infarction. ${ }^{14}$

Most of the earlier trials studying the possibility of limiting infarct size by different types of intervention have not focused on the incidence and severity of congestive heart failure. In one of these, ${ }^{8}$ however, atenolol given $\leqslant 12$ hours after onset of pain in myocardial infarction decreased the need for frusemide during admission to hospital. In that study no patients were included who were treated after a longer delay, and an open study design was used.

The doctors treating the patients in the present trial were, with few exceptions, not involved in the conduct of the trial. They were not aware of how the patient had reacted to the blind injection since the protocol was not available after the initial injection. Furthermore, the doctors were unaware of how long after the onset of pain treatment with metoprolol was started.

In previous large trials of beta blockers, in which treatment was started after the acute stage, more problems with heart failure were observed in the patients treated with beta blockade, although mortality was reduced. ${ }^{1516}$ In the present study, in which treatment was started as early as possible after admission to hospital heart failure seemed to occur less often in patients given beta blockade. The most reasonable explanation is a limitation of the infarct size.
This study was supported by grants from the Swedish Medical Research Council, the Swedish National Association against Heart and Chest Diseases, the Göteborg Medical Society, and AB Hässle, subsidiary of Astra Pharmaceuticals, Sweden. The data in Fig. 2a are published by kind permission of the American foumal of Cardiology.

\section{References}

1 Awan NA, Miller RR, Vera Z, Janzen DA, Amsterdam EA, Mason DT. Noninvasive assesement of cardiac function and ventricular dyssynergy by precordial $Q$ wave mapping in anterior myocardial infarction. Circulation 1977; 55: 833-8.

2 Bleifeld W, Mathey D, Hanrath P, Buss H, Effert S. Infarct size estimation from serial serum creatine phosphokinase in relation to left ventricular hemodynamics. Circulation 1977; 55: 303-11.

3 Kahn J-C, Gueret P, Baudet M, Rocha P, Bardet J, Bourdarias $\mathrm{J}-\mathrm{P}$. Clinical assessment of infarct size by serial determinations of serum creatine phosphokinase activity. Eur f Cardiol 1979; 9: 21-37.

4 Busemann W-D, Passek D, Seidel W, Kaltenbech M. Reduction of creatine kinase, creatine kinnse-MB, and infarct size by intravenous nitroglycerin. In: Kreuzer H, Parmley WW, Rentrop P, Heiss HW, eds. Quantification of myocandial ischemia. (Advances in Clinical Cardiology, vol. 1.) New York: Witztrock, 1980:536-41.

5 Maroko PR, Deboer LWV, Davis RF. Infarct size reduction: a critical review. Ado Candiol 1980; 27: 127-69.

6 Durrer JD, Lie KI, van Capelle FJL, Durrer D. Effect of sodium nitroprusside on mortality in acute myocardial infarction. $N$ Engl f Med 1982; 306: 1121-8.

7 Peter T, Norris RM, Clarke ED, et al. Reduction of enzyme levels by propranolol after acute myocardial infarction. Circulation 1978; 57: 1091-5.

8 Yusuf S, Peto R, Bennett D, et al. Early intravenous atenolol treatment in suspected acute myocardial infarction. Lancet 1980; ii: $273-6$.

9 Jürgensen HJ, Frederilesen J, Hansen DA, Pedersen-Bjergaard O. Limitation of myocardial infarct size in patients less than 66 years treated with alprenolol. $\mathrm{Br} \mathrm{Hean}$ f 1981; 45: 583-8.

10 Hjalmarson A, Elmfeldt D, Herlitz J, et al. Effect on mortality of metoprolol in acute myocardial infarction. A double-blind randomised trial. Lancet 1981; ii: 823-7.

11 Herlitz J, Elmfeldt D, Hjalmarson A, et al. Effect of metoprolol on indirect signs of the size and severity of acute myocardial infarction. Am I Cardiol 1983; 51: 1282-8.

12 Brydon WG, Smith AF. An appraisal of routine methods for the determination of the anodal isoenzymes of lactate dehydrogenase. Clin Chim Acta 1973; 43: 361-9.

13 Committee on Enzymes of the Scandinavian Society for Clinical Chemistry and Clinical Physiology. Recommended methods for the determination of four enzymes in blood. Scand f Clin Lab Inoest 1974; 33: 291-306.

14 Herlitz J, Waldenström J, Hjalmarson A. Relationship between the enzymatically estimated infarct size and clinical findings in acute myocardial infarction. Acta Med Scand 1984; 215: 21-32.

15 Norwegian Multicenter Study Group. Timolol-induced reduction in mortality and reinfarction in patients surviving acute myocardial infarction. $N$ Engl $f$ Med 1981; 304: 801-7.

16 Beta-Blocker Heart Attack Trial Research Group. A randomized trial of propranolol in patients with acute myocardial infarction. I. Mortality results. $\mathcal{F A M A} 1982 ; 247$ : 1707-14. 